\title{
EDITORIAL
}

\section{Por una muerte digna para la educación artística}

For a death with dignity for art education

\author{
Ricard HUERTA. Universitat de València (España). ricard.huerta@uv.es \\ Ricardo DOMíNGUEZ. Universitat de València (España). \\ ricardo.dominguez@uv.es
}

\begin{abstract}
Resumen: El año 2020 ha estado marcado por una pandemia global causante de una situación extraña e impredecible a nivel planetario. Todos los países del mundo se encuentran en procesos de prevención sanitaria contra la COVID-19, un virus que ataca agresivamente el sistema inmunológico de las personas. Intentar llevar a cabo cualquier actividad supone un riesgo de contagio, ya que el coronavirus se propaga sobre todo a través del aliento humano, lo cual ha supuesto la irrupción de nuevos hábitos cotidianos, como usar siempre la mascarilla, o no poder reunirse con otra gente para celebraciones y eventos, ni tampoco dar clase en el aula. Inmersos en esta tesitura, desfavorable para cualquier intento de normalidad educativa, en el caso de la educación artística padecemos doblemente esta penosa realidad. En la coyuntura española, iniciábamos el año presentando una serie de alegaciones a la nueva ley de educación que el gobierno quiere aprobar (LOMLOE), una ley que prácticamente elimina las artes visuales del currículum escolar. También en otros países se está evidenciando un retroceso constante en materia de educación artística. Si el coronavirus está impulsando la práctica de las artes mediante el uso de tecnologías digitales, y la sociedad reivindica más enseñanzas en materia de prevención, salud, inclusión, igualdad, diversidad y lenguajes tecnológicos emergentes, deberíamos atender a estas necesidades que requiere el nuevo escenario educativo y vital. Ante tales evidencias, apostamos por una muerte digna de nuestra especialidad, tal y como la entendíamos hasta ahora, valorando que este derecho a la eutanasia supone el nacimiento de un concepto renovado de la educación artística, algo que deberemos abordar como prioridad y de manera inmediata.
\end{abstract}

Palabras clave: arte, educación artística, pandemia, formación de profesorado, coronavirus. 


\begin{abstract}
This year 2020 has marked by a global pandemic that causes a strange and unpredictable situation at the planetary level. All countries are in health prevention processes due to COVID-19, a virus that attacks the immune system. Trying to do any activity poses a risk of contagion, since the coronavirus spreads especially through human breath, which has led to the invasion of new daily habits, such as leaving the house with a mask, or not being able to meet other people for celebrations and events, or to teach in the classroom. Immersed in this unfavorable situation for any educational normality, in the case of artistic education we suffer doubly from this painful reality. In Spain, we started the year presenting a series of complaints to the new education law that the government wants to pass (LOMLOE), a law that practically eliminates the visual arts from the school curriculum. Also in other countries, there is a constant decline in Art Education as curricular teaching. If the coronavirus is promoting the use of digital technologies, and society claims the teachings on prevention, health, inclusion, equality, diversity and emerging technological languages, we should attend to the needs required by the new educational and vital scenario. Faced with such evidence, we are committed to a death worthy of our specialty, as we understood it until now, understanding that this right to euthanasia implies the birth of a renewed concept of artistic education, something that we must do immediately as a priority.
\end{abstract}

Keywords: Art, Art Education, Pandemic, Teacher Training, Coronavirus.

\title{
Una muerte digna de lo que venía siendo un lastre en la educación artística
}

La situación de crisis sanitaria está desbordando numerosos aspectos primordiales como la economía, el comercio, la salud, el trabajo, y en general todas las relaciones sociales. Lo que está sacando a la luz esta pandemia son algunas injusticias que permanecían excesivamente ocultas, como el papel de los fondos buitre en determinados escenarios de sanidad y educación (especialmente residencias de ancianos y de estudiantes), o la poca capacidad de reacción institucional en materia educativa y sanitaria (algo que resulta muy evidente en países como Estados Unidos o Brasil). Es en esta situación descontrolada que lo educativo está padeciendo mayores injerencias, agresiones constantes que se justifican en la mayoría de casos bajo el paraguas de la "crisis sanitaria". Frente a las improvisaciones constantes por parte de gobernantes y responsables políticos, observamos que el colectivo docente ha dado un buen ejemplo de saber hacer, habiendo afrontado la situación con muchísima energía, apostando fuerte por todo aquello que pudiese favorecer lo educativo, dentro de los márgenes que permiten la seguridad y la salud de las personas. Prueba de ello es el esfuerzo considerable que el profesorado ha hecho para seguir manteniendo la actividad escolar, incluso durante el estado de alarma, aprovechando los recursos tecnológicos a su alcance. 
Es precisamente en el uso de las tecnologías digitales donde encontramos una mayor posibilidad de apoyo hacia la educación en artes visuales. ¿Alguien no se ha dado cuenta todavía? El escenario digital está repleto de imágenes, y es precisamente el universo de las imágenes el que nos corresponde como especialistas en artes visuales. Deberíamos reflexionar detenidamente sobre las posibilidades que ofrece la Educación Artística en un momento en el que las desubicaciones online se han apoderado de buena parte del entorno educativo. Nuestra capacidad para manejar las tecnologías de la imagen nos dará la posibilidad de avanzar en el terreno de afianzarse sólidamente en el seno del currículum escolar. La fotografía, el video, los videojuegos, las pantallas, los dispositivos móviles, y en general todos los conceptos y usos digitales están incorporándose a nuestras vidas, de modo que ya no podemos permanecer ajenos a esta urgencia educativa y artística. Así las cosas, la lección de la pandemia es que desde la educación en artes debemos atender la efervescencia de lo digital, un universo repleto de imágenes.

\section{La imagen digital augura una muerte digna de la educación artística tradicional}

Quienes nos dedicamos profesionalmente a la educación artística somos conscientes del avance irrefrenable que ha tenido en estos últimos tiempos el desarrollo digital, así como la implantación de Internet como referencia para la impresionante actividad en red. Pantallas, webs, blogs, links, apps, fakes, selfies, likes, y todo tipo de usos o herramientas han venido a renovar la acción educativa. La creación y difusión de imágenes en pantallas ha significado un aumento exponencial de las necesidades de la población en materia de conocimiento del lenguaje visual. Los profesores de artes somos expertos en imágenes, y debemos reivindicar esta realidad si queremos renovar la educación artística, poniéndola en el lugar que merece dentro del sistema educativo (Buckingham, 2008). Del mismo modo que ha ocurrido con lenguajes como el matemático, el verbal o el musical, en los que sus especialistas han tomado fuerza en el panorama escolar, desde la educación artística debemos asumir que nuestro lenguaje es el de las imágenes (Duncum, 2015). Por tanto, y más allá del concepto de alfabetización visual, que ya nos resulta muy familiar (Dondis, 2017), lo que debemos hacer es tomar partido por la enseñanza de las imágenes. Es algo que la ciudadanía necesita, y nosotros podemos hacer un maravilloso trabajo de concienciación al respecto (Benjamin, 2003). Somos nosotros quienes más sabemos de imágenes, de su creación y de su estudio. Por tanto, somos quienes podemos educar para observar, crear y difundir imágenes. ¿A qué estamos esperando?

El concepto de eutanasia, lo que ahora reivindicamos para la educación artística bajo el eufemismo retórico de "muerte digna", nos lleva irrevocablemente hacia la recuperación de un documento audiovisual de gran calado: la película de Alejandro Amenábar Mar adentro, interpretada por Javier Bardem. En Mar adentro se nos cuenta una historia real, la de un hombre que luchó durante años por salir de la prisión en la que se había convertido su propio cuerpo. Algo similar nos ocurre con la 
educación artística. Aspectos tradicionales como la libre expresión, la creatividad o la retórica artística, nos han postrado en una camilla en la que a veces da la sensación que nos encontramos cómodos. Permanecemos sin movilidad, pero con vida, muy a pesar de los esfuerzos constantes por evolucionar. Se nos mantiene vivos, pero no es el mejor modelo de existencia deseable. Para salir de esta situación desfavorable, para superar esta fase de inmovilidad, lo que podemos hacer es replantearnos nuestra situación, abrir nuevos caminos, avanzar en todo aquello que nos pueda favorecer, a saber: la investigación, la creación, el impulso tecnológico, la interpretación de las imágenes, el uso de pantallas y dispositivos móviles, la atención a las problemáticas sociales, la reivindicación de espacios de reconocimiento como la arteterapia y las políticas de inclusión, la lucha por los derechos humanos. Debemos permanecer atentos a todas estas emergencias, puesto que constituyen geografías muy fértiles para la educación en artes. Y para un renacer fecundo de la educación en artes, entre las posibilidades que destacamos estarían las siguientes:

- Las imágenes como lenguaje que se puede enseñar y aprender.

- La tecnología digital como campo esperanzador en tanto que ámbito repleto de imágenes.

- El acercamiento a la iconografía como foco de conocimiento personal y colectivo.

- La cultura visual como campo de acción comunicativa.

- Las reivindicaciones sociales que acompañan al arte contemporáneo.

- La creación visual y audiovisual como futuro laboral de las generaciones más jóvenes.

- El reconocimiento personal y el factor identitario como fuente de investigación y docencia.

- La neurociencia y su papel en la sensibilización artística respecto al imaginario colectivo.

- El diseño gráfico y el diseño digital, tan apreciados por las generaciones más jóvenes.

Todas estas posibilidades, y muchas más que están por venir, nos facilitarán un cambio de estrategia a nivel coyuntural, propiciando así un verdadero renacimiento de la probablemente ya desgastada educación artística convencional.

\section{Al menos morir, y renacer de un modo espectacular, como en un videojuego}

Mientras la educación artística y sus profesionales seguimos perdiendo fuelle en el escenario educativo curricular, los videojuegos se consolidan como la mayor industria del entretenimiento, tanto en número de usuarios como de negocio comercial. Lo cierto es que la imagen es uno de los elementos determinantes del videojuego como medio de comunicación y entretenimiento. Debemos ser ágiles 
y encontrar nuestro espacio académico en un entorno donde los videojuegos, las series de televisión, los videoclips, las tendencias del arte digital y el audiovisual en general, están abanderando procesos complejos y muy atractivos. ¿A qué estamos esperando? Da la sensación de que seguimos ajenos a las nuevas prácticas y hábitos de la ciudadanía. Para evitarlo, mejor nos ponemos a trabajar con temáticas como las siguientes: la implantación tecnológica y el uso masivo de dispositivos móviles en el aula y fuera de ella (Mascarell, 2017); las posibilidades de los entornos virtuales en las clases (Domínguez, 2019); la crítica al mercado del arte como especulación (Santamaría, 2019); el audiovisual como experiencia vital del alumnado (Arcoba, 2019); el cine educativo como campo de acción y de estudio (Augustowsky, 2019; Monleón, 2018, 2020); la educación patrimonial (Fontal, García Ceballos y Aso Morán, 2020); la diversidad sexual (Huerta, 2017; Huerta y Alonso-Sanz, 2015); el papel de los museos en la educación artística (Soto González, 2015; Vidagañ, 2016); los procesos vinculados a las identidades (Huerta, 2020); el posthumanismo y las entidades cyber (Haraway, 2019); los temas ambientales y de preservación del planeta (Otxoteko, 2020); el ecosistema de la visualidad (Patiño, 2017); el apego a la vertiente curricular (Huerta, 2019); la cognición expresiva y la metaemoción (Caeiro Rodríguez, 2018; Caeiro Rodríguez y Muñiz de la Arena, 2019) las narrativas e historias de vida (Hernández-Hernández y Sancho, 2020); las derivas pedagógicas y visuales (Ramon, 2019; Ramon y Alonso-Sanz, 2019); las pedagogías sensibles (Planella, 2017); las Humanidades Digitales (Huerta y Alonso-Sanz, 2020); la investigación basada en artes (Marín y Roldán, 2017); y desde luego las cuestiones de arte y salud (Hernández Belver y Ullán, 2017).

Nuestro ámbito de actuación sigue vinculado directamente a la imagen, el campo de acción más extraordinario en el que nos movemos. Más allá de nuestra estrecha relación con las artes, lo que debe predominar es nuestro posicionamiento de futuro es el papel que jugamos como expertos respecto al lenguaje de las imágenes. Teniendo en cuenta que las tecnologías digitales han impulsado un uso mayoritario y masificado de dichas imágenes. Valorando sobre todo que estamos en el momento histórico en que más imágenes se crean, se difunden y desaparecen a cada instante. ¿Cuál es nuestro papel en la sociedad que está forjando la crisis del coronavirus?

Si en el universo de la comunicación y el entretenimiento está definido por las imágenes, de modo que nuestro capital simbólico está repleto de películas y series, de videoclips y videojuegos, de difusión en redes de mensajes que nosotros mismo generamos, deberíamos atender a estrategias adecuadas, utilizando posibilidades creativas rebeldes desde las aulas, especialmente allá donde tenemos especialistas en artes. De hecho, en la actual edición del proyecto Second Round: Arte y lucha en Secundaria, la temática versa sobre videojuegos, cómic e ilustración (Gómez Aguilella, 2018). Ahora que la lección de la COVID-19 nos ha revelado hacia dónde se encaminan los flujos educativos, ahora es cuando más contundente debe ser nuestra respuesta, como especialistas en imágenes que somos. 


\section{\#EducacionNoSinArtes}

La pandemia y las situaciones adversas que genera, como los confinamientos o estados de excepción, han traído a los hogares y al resto de espacios privados, mucho más arte y educación artística de la que jamás se había podido ver fuera de las aulas. Esta situación propicia para la práctica de las artes, que encaja y se corresponde con el gran auge que viene tomando la práctica artística en general, contrasta con la poca presencia de las artes en el currículum oficial. A mayor vitalidad artística fuera de las escuelas, menor interés administrativo por potenciar las artes en las aulas. Frente a dicha descompensación, son numerosas las voces que se han alzado para mejorar las causas y consecuencias de estos desequilibrios. El profesorado de artes busca su lugar, dentro y fuera de los centros educativos.

Una de las campañas de concienciación hacia la educación en artes que más repercusión han tenido, al menos en el panorama español, es la que representa el hashtag \#EducacionNoSinArtes que también se está retwitteando en otros países como movimiento de respuesta a una situación adversa, que conlleva una movilización que se repite. Sin llegar a tremendo efecto global del \#MeeToo, pero con una intención similar, este eslogan reivindicativo ha tomado mucha fuerza, y está propiciando avances, al menos en algunos países concretos. Debido a la poca eficacia de organizaciones internacionales como InSEA, que deberían estar luchando codo a codo con las fuerzas locales, pero que sin embargo se mantienen ausentes del escenario de protesta, han sido los colectivos de arteducadores quienes han encendido la llama de una renovación necesaria, de una educación no sin artes.

Desde el grupo de whatsapp Educación Artística ha sido posible unir esfuerzos de centenares de especialistas, contagiando al conjunto de ansia por avanzar juntos. Algo tan sencillo como un grupo en una aplicación informática en red ha propiciado ya dos encuentros, uno en Girona y otro en Bilbao. El siguiente congreso, ya con periodicidad bianual, tendrá lugar en enero de 2022 en València, aprovechando la capitalidad mundial del diseño, que ha reconocido a la ciudad como escenario de esta efeméride. Precisamente el diseño debería formar parte de nuestra carta de navegación (Huerta, Alonso-Sanz y Ramon, 2018; Lovink, 2019). Mientras tanto, las acciones del grupo continúan y se expanden en redes, como es el caso del decálogo que describimos a continuación en sus diez puntos o argumentos de cambio y mejora de la LOMLOE:

1. Creación de una "mención a la especialidad en Educación Artística: artes plásticas, visuales y audiovisuales" con la correspondiente modificación del Real Decreto 1594/2011 que regula las diferentes especialidades docentes en las etapas de Educación Infantil y Primaria. El hecho de que la formación de maestros y maestras sea generalista, salvo en aquellas menciones que se ha considerado que requieren de una especialización, nos indica que hay conocimientos que exigen una formación más experta en algunos campos, técnicas y contenidos. La existencia 
de las menciones y especialidades vigentes demuestra que no todos los saberes pueden asumirse o producirse en un marco común curricular. Sin duda alguna, la comunidad docente del Área de Expresión Plástica de las Facultades de Educación considera que la formación en artes plásticas, arte y cultura visual y audiovisual, arte contemporáneo, educación patrimonial, diseño y todo aquello que con cada uno de estos campos se relaciona, requiere de un espacio curricular específico y una especialización docente que aporte claridad y calidad, permitiendo así desarrollos más amplios y una mejor formación.

2. Incremento de la carga lectiva de la educación artística tanto en Educación Primaria como en Secundaria. La importancia de la enseñanza de las artes para una formación integral hace imprescindible el incremento de las horas dedicadas a esta materia en todas las etapas del proceso formativo. En Primaria, separando la Educación Artística: Plástica, Visual y Audiovisual de la Educación Musical para poder trabajar progresivamente y en desarrollos efectivos en lo que les es propio. La nueva Ley de Educación debe contener alguna precisión y mención a este respecto, para garantizar un profesorado especialista, el correcto desarrollo curricular y la impartición real de estos contenidos.

\section{Consideración de la Educación Plástica, Visual y Audiovisual como una materia} "común" en la ESO e "instrumental" en Primaria, y no específica u optativa. En el actual proyecto de ley, y debido a su carácter específico y opcional, puede darse la posibilidad que en un centro lleguen a no cursarse asignaturas artísticas al quedar al arbitrio de la Comunidad Autónoma. Este cambio supone asegurar la dotación de los recursos estructurales (tiempo de carga lectiva semanal, de la hora actual a tres horas semanales) e infraestructurales (materiales, espacios), adecuados y suficientes para desarrollar la asignatura, acordes con los objetivos que se deben conseguir competencial y curricularmente. De esta forma, sería posible garantizar la equidad del Sistema Educativo Español a la que se hace referencia en el texto del Proyecto de Ley, tanto en sus principios como en sus fines.

4. Consideración de la Educación Artística como materia fundamental e imprescindible para afrontar los retos del Siglo XXI. Es la Educación Artística la que ha desarrollado en los últimos tiempos mayor investigación en torno a cómo trasladar al aula de forma didáctica: 1) los avances de campos de la psicología sobre creatividad, 2) los usos de la tecnología desde la alfabetización audiovisual, como personas creadoras de visualidades y creaciones audiovisuales, pero también como consumidores y usuarios críticos de las pantallas y sus contenidos en una sociedad prosumidora, 3) el aprendizaje basado en proyectos originario de las artes que desarrolla competencias, 4) las estrategias para desarrollar un pensamiento divergente y creativo a través de la creación artística que repercuta en profesiones tan dispares como el diseño, la ingeniería, la arquitectura u otras profesiones de carácter científico. 
5. Valoración de la Educación Artística como oportunidad de enriquecimiento formativo y profesional de todo el alumnado y la ruptura de estereotipos asociados. Entre los nuevos cambios educativos que se destacan de la LOMLOE se encuentra para la educación en la etapa de bachillerato el "refuerzo de la igualdad efectiva de derechos y oportunidades entre hombres y mujeres" y "4. En todo caso, las Administraciones educativas impulsarán el incremento de la presencia de alumnas en estudios del ámbito de las ciencias, tecnología, ingeniería, artes y matemáticas, así como en las enseñanzas de formación profesional con menor demanda femenina.". Uno de estos contextos en los que se incidirá educativamente buscando la ruptura estereotipada de las profesiones es en el denominado modelo STEAM (Ciencia, Tecnología, Ingeniería, Arte y Matemáticas, por sus siglas en inglés) cada vez más presente en la etapa de secundaria y los ciclos formativos. Si bien es lógico aumentar las vocaciones STEAM, especialmente entre las mujeres, también es imprescindible aumentar las vocaciones vinculadas a las Artes y Humanidades en ambos géneros. De otro modo se perpetúa la segregación de vocaciones por sexos.

6. Educación Artística como contexto idóneo para trabajar temas vitales para la sociedad actual. Entre los nuevos cambios educativos que se destacan de la LOMLOE se encuentra, para la educación secundaria, la "educación en valores cívicos y éticos", así como el "refuerzo de la orientación con perspectiva de género". El aprendizaje en valores no puede darse desconectado del contexto sociocultural del alumnado, sino de forma situada. La Educación Artística desarrolla proyectos de carácter educativo vinculados a las vindicaciones que tradicionalmente el arte contemporáneo hace de los problemas e injusticias sociales más actuales (en las últimas décadas temas centrales han sido SIDA; inmigración; desahucios; violencia de género y feminismos; pobreza infantil; diversidad funcional, cultural, religiosa, sexual, entre otros). Además, la educación en valores cívicos y éticos debe tener un carácter propositivo $\mathrm{y}$, desde la educación artística, la teoría se convierte en propuestas prácticas de aprendizaje servicio, de expresión pacífica de intereses, de sensibilización comunitaria, de arte participativo.

7. Educación Artística para una sociedad reflexiva, crítica, creativa y responsable con la realidad actual. El objetivo 1 de la LOMLOE, con el propósito de modernizar el sistema educativo, plantea "educación para una ciudadanía activa, crítica y global". En un mundo globalizado a través de las redes sociales, conectado a través de las tecnologías y bombardeado por visualidades que afectan y configuran las identidades, el papel de la Educación Artística para alfabetizar visual y audiovisualmente a la población infantil y juvenil es fundamental. El pensamiento reflexivo, crítico, creativo y responsable debe hacerse a partir de los productos de la cultura visual y audiovisual que el alumnado consume fuera de las aulas y que debe ser traído al espacio de la institución escolar.

8. Educación Plástica, Visual y Audiovisual para la formación integral del alumnado y desarrollo como persona. La asignatura de Educación Plástica, Visual 
y Audiovisual resulta imprescindible en la actual sociedad dentro de la formación integral del alumnado. En una sociedad tecnológica y mediática, centrada en la transmisión de información de carácter visual y audiovisual, esta asignatura resulta vital para la formación de las generaciones actuales y futuras. Por ello es importante que sea desarrollada por especialistas en la materia en primer lugar, y no de forma transversal a través de otras disciplinas. El acercamiento a las imágenes como vehículo de expresión y comunicación de ideas y emociones y la creación artística como experiencia, ya desde la primera infancia se contribuye a estructurar cognitivamente la mente para reconocer y expresar emociones y generar y comunicar ideas. Además, la educación artística genera modos de encontrarnos con nosotros mismos y comunicarnos con las demás personas favoreciendo la empatía.

\section{Respeto por la profesión y la formación experta del Profesorado de Educación} Artística. En la etapa de Secundaria es importante garantizar que las materias relacionadas con las artes y contenidos afines sean impartidas por el profesorado del área de educación artística.

10. Revisión de los perfiles del profesorado de artes y formaciones habilitantes para acceder a las plazas docentes en oposiciones, tanto en Primaria como en Secundaria y en la Universidad. Garantizar una mayor formación en Artes de los maestros y maestras a través de una Mención en Educación Artística durante el Grado en relación directa con nuestra área de conocimiento, con prácticas específicas durante su formación para la aplicación y experimentación directa en las aulas de Primaria. Asimismo, se considera necesaria la revisión de las titulaciones que permiten acceder al Máster de Formación de Secundaria y cursar la especialidad relacionada con Artes, la cual habilita a posteriori para presentarse a las oposiciones en esa etapa educativa, por ejemplo, en la especialidad de Dibujo, Imagen y Artes Plásticas.

Suscribe este escrito el profesorado del Área de Didáctica de la Expresión Plástica de las Facultades de Educación y de Bellas Artes de universidades españolas.

\section{Escenarios de diversidad, escenarios de igualdad}

Desde el grupo CREARI de Investigación en Pedagogías Culturales(GIUV2013-103) hemos convocado en este 2020 dos encuentros en los que se plantean las cuestiones de género y diversidad para mejorar el respeto hacia las mujeres y las minorías disidentes desde los feminismos y la diversidad sexual. En CREARI celebramos la organización de las "1as Jornadas de Sensibilización en igualdad de género y diversidad sexual mediante intervenciones artísticas en contextos universitarios" www.uv.es/creari/congressos/jornadassensibilizacion en las que participan artistas y profesores de varias universidades para incentivar estas cuestiones, desde la acción y la reflexión académica. Las Jornadas están dirigidas por la profesora Amparo Alonso Sanz, investigadora principal de un proyecto de investigación subvencionado del que forma parte esta actividad. En la misma línea de trabajo 
académico se encuadran las "Jornadas Transeducar: Feminismos y Disidencias LGTB", que son en realidad las "X Jornadas Internacionales de Investigación en Educación Artística", una actividad que se inició en 1997, y que continúa activa en la Universitat de València. La presencia de invitados internacionales, de siete países distintos, convierten estas Jornadas Transeducar www.uv.es/creari/transeducar en un referente de los procesos que atañen a la irrupción de estas problemáticas en el entorno académico de la investigación y la educación en artes. A pesar de las dificultades provocadas por la pandemia, tanto las "Jornadas de Sensibilización" como las "Jornadas Transeducar" tienen formato presencial, además de contar con una versión retransmitida en digital, que se ofrece en abierto para todo el mundo.

Las cuestiones vinculadas a los feminismos y las disidencias sexuales están muy presentes en numerosos lugares de Latinoamérica (Barbosa y Amaral, 2019), especialmente en Brasil, donde el "Seminario Arte, Gênero, Ensino" y otras tantas iniciativas, suponen un fuerte aliento para mejorar la investigación en educación artística con relación a temáticas de diversidad e igualdad. El auge de las políticas públicas de diversidad e igualdad deben favorecer un mayor apoyo hacia las iniciativas que surgen desde todos los puntos del planeta para defender los derechos de las mujeres y de los colectivos de la diversidad sexual. Investigar estas cuestiones y llevarlas al territorio de la investigación y la docencia, que permitirán también un auge y desarrollo de las posibilidades que esconde la educación en artes. Igualmente conviene tener presente todo lo bueno de nuestra tradición (Barbosa, 2015), activando estudios que promuevan el descubrimiento de figuras poco conocidas (Macharowski, 2019). Podemos transformar las actividades del aula a través del cine (Huerta, Alonso-Sanz y Ramon, 2019), las series y los videojuegos. Hemos de seguir muy pendientes de aquello que resulte atractivo para el alumnado. En este sentido, los audiovisuales y las imágenes en general constituyen un entorno muy adecuado para llevar adelante nuestra acción docente, implicándonos en problemáticas sociales y personales. Luchar por los derechos de las minorías y marginalidades siempre resulta beneficioso, especialmente en un escenario global de conservadurismo neoliberal aplastante como el actual, por lo que no debemos perder de vista nunca las lecciones de grandes referencias intelectuales como Zigmut Bauman (2017), Paulo Freire (2015) y Henry Giroux (2015).

\section{Artículos de la revista EARI número 11}

En el número 11 de la revista EARI se presentan un total de once artículos, además de una entrevista, en este caso a tres profesionales destacados, y cinco recensiones de libros. Constatamos la presencia de artículos internacionales, lo que avala el carácter global de nuestra publicación, como en ediciones anteriores. La visión plural que obtenemos a través de estos artículos nos permite realizar diversas aproximaciones a la educación artística y nos ofrece peculiares marcos teóricos que ayudan a entender mejor la evolución del área de conocimiento, sus fines y el papel relevante que debe tener en la formación de las personas. 
De este modo el trabajo de Roberto Jiménez, Un docente revolucionario para la formación artística (decolonial) contemporânea, reflexiona sobre la figura del docente y su papel en diferentes modelos pedagógicos. En el contexto actual su propuesta reivindica la figura del docente como agente movilizador en la creación compartida con el alumnado de nuevos modelos surgidos de las necesidades actuales. Su premisa de educar desde la "decolonialidad" se articula desde una comprensiòn crítica y reflexiva de las subjetividades, frente al monopolio del pensamiento único o dominante.

En "Infancias mediadas": narrativas visuales en la formación del profesorado, Alfonso Carrasco, Carme Molet, Dànae Quiroz y Olga Bernad presentan un proyecto mixto de Investigación-acción y de Investigación educativa basada en las artes, llevado a cabo en la Facultad de Educación Psicología y Trabajo Social de la Universidad de Lleida. La investigación constata la importancia de cuestionar algunos mitos y discursos sobre "la infancia", a fin de asumir responsabilidad educativa hacia las diferentes infancias planteando otras formas de construcción crítica de identidades docentes, relacionando las prácticas artísticas, las visualidades y las pedagogías críticas.

En el contexto de la Educación Secundaria el artículo Educación artística y teorías implícitas del alumnado de educación secundaria, de Cristina Navarrete, Carmen Rodríguezy José Luis Belver, analiza las teorías implícitas de los estudiantes de laESO en relación conlaEducaciónArtística, manifestándosela pervivencia de determinados mitos o ideas preconcebidas, que suponen un obstáculo para su aprendizaje.

En la formación de los futuros docentes de Secundaria el artículo El cuerpo como dispositivo didáctico en la formación inicial docente en artes visuales para enseñanza secundaria, de Luis Claudio Cortes, Noemi Grinspun, Sandra Medin y Claudio Humberto Oyarzún, nos ofrece una experiencia pedagógica cuyo objetivo principal es reflexionar teóricamente en torno al cuerpo y sus posibilidades pedagógicas. Finalmente se sugieren tres talleres interdisciplinares que entrelazan literatura, teatro y cine, a partir del lenguaje y expresión corporal para programas de formación inicial de profesores/as en artes visuales.

Varios artículos destacan la vinculación del cine con la educación. Así el trabajo El cine y la enseñanza del arte en Brasil: una mirada a concepciones y experiencias modernistas, presentado por Sidiney Peterson F. de Lima, realiza una revisión de las prácticas desarrolladas en el campo de la formación del professorado en Brasil, en particular las experiencias llevadas a cabo en el Curso Intensivo de Arte en la Educación (CIAE) a partir de los años sesenta, en las que se destaca el papel educativo del cine.

Apolline Torregrosa, en Cine directo, aproximaciones pedagógicas de lo cotidiano, explora también la dimensión educativa del cine a partir de las aportaciones del 
género de cine directo. Partiendo del análisis de fragmentos de la película National Gallery de Frederick Wiseman se muestra cómo el cine directo nos hace descubrir de un modo más interactivo, más sensible, las situaciones de las instituciones y nos invita a repensar nuestras formas de interactuar entre los protagonistas de la educación y de la investigación.

Y en Patrones malvados en Disney. Una reflexión crítica sobre las figuras malvadas de la colección "Los clásicos" (1937-2016) desde un componente estético, Vicente Monleón expone la visión maniquea construida en los relatos de las animaciones de Disney a partir del análisis crítico y reflexivo de las 60 películas de las que está compuesta la colección cinematográfica de animación "Los clásicos" Disney.

En relación con los nuevos discursos construidos en la red y la tecnología Javier Domínguez, en El fenómeno de la mirada y el concepto de lugar. Una propuesta de aprendizaje basado en proyecto con videocreación e Internet, en el contexto del Grado en Educación Primaria, presenta una experiencia cuyos objetivos pedagógicos se basan en entrenar un lenguaje estético en el régimen de lo visual, y generar un discurso ético-político a partir de las narrativas visuales. A partir de una metodología activa de aprendizaje basado en proyectos su propuesta conjuga dos fuentes de material visual para construir narrativas: la propia videocreación, y las imágenes-archivos capturables de la aplicación Street View. Todo ello nos invita a pensar de una manera crítica en la identidad, tal como aparece en las pantallas.

La propuesta de Hishochy Delgado, Yasselle Angela Torres y Maylín Alonso, Educación crítica de las artes visuales en estudiantes de diseño gráfico. Relaciones de aprendizaje en torno a la cultura visual, aborda el andamiaje contextual que sitúa al discurso crítico como una necesidad educativa en estudiantes de Diseño Gráfico. Su investigación parte de un análisis de los componentes curriculares de los estudios de Diseño en la Pontificia Universidad Católica del Ecuador, indagando de qué modo intervienen en las decisiones para conformar un aparato crítico hacia el objeto artístico visual.

Ricard Balanzà, en su artículo Una experiencia artística con tierra, barro y cerámica, presenta una práctica desarrollada en el contexto universitario en la formación de futuros docentes de Primaria a partir de la cerámica. En ella, paralelamente a los contenidos teóricos y las técnicas plásticas desarrolladas, se motiva un sentido crítico, estético y sensible a partir del debate y análisis de obras de arte contemporáneo y su diálogo entre lenguajes y disciplinas.

En relación con la valoración y difusión del patrimonio cultural e identitario el artículo Los cimientos de La Casa de las Luces. Enclave rural en clave cultural, de Virgina Zanón, muestra los primeros pasos de La Casa de las Luces, un proyecto cultural que nace con el objetivo de poner en valor y divulgar el rico patrimonio cultural y natural del pueblo de Titaguas, municipio situado en la comarca de La 
Serranía, en el interior de la provincia de Valencia. Se muestran las particularidades de este proyecto y las ventajas e inconvenientes que surgen en el establecimiento de un centro de nueva creación.

La entrevista realizada por Ricard Huerta bajo el título Educación artística más allá del coronavirus: diálogo con Estitxu Aberasturi, Carlos Escaño y Carmen María Belmonte, nos muestra las miradas de tres profesionales muy implicados en la realidad de la educación en artes: Estitxu Aberasturi, profesora de la UPV-EHU, Carlos Escaño, profesor de la Universidad de Sevilla y Carmen María Belmonte profesora del Instituto de Educación Secundaria Lluís Vives de València. Esta conversación nos ofrece una oportunidad para escuchar tres voces relevantes en el panorama de la reflexión sobre el marco en el que se están desarrollando los distintos ámbitos y tendencias de la enseñanza de las artes.

Finalizamos este relato haciendo referencia a la portada de este número. La fotografía de la portada se corresponde a la performance Bagagem de Shambuyi Wetu en el Seminário Arte/Gênero/Ensino. El Seminario tuvo lugar del 12 al 16 de agosto de 2019 en el Centro de Artes de la URCA Universidad Regional do Cariri, ubicado en la ciudad de Crato (Ceará) (Huerta, 2019). A través de esta intervención el artista, que llegó en barco a Brasil en 2014 como refugiado político de la República Democrática del Congo, retrata la realidad de los refugiados, y cómo los países los reciben como cuerpos, relegando su bagaje personal e intelectual. El saco sobre su rostro nos remite de nuevo a otras invisibilidades, que desde el área debemos contribuir a visibilizar.

\section{Referencias}

Arcoba, M. D. (2019). La creación audiovisual en educación artística. Un estudio a partir de autorretratos e identidades desde la videocreación. Tesis doctoral. València: Universitat de València.

Augustowsky, G. (2019). La creación audiovisual en la infancia. Estudio de experiencias en contextos educativos. EARI Educación Artística Revista de Investigación, 10, 235-250. Doi: https://doi.org/10.7203/eari.10.13922

Barbosa, A. M. (2015). Redesenhando o Desenho, educadores, politica e história. Sao Paulo: Cortez Editora.

Barbosa, A. M.; Amaral, V. (2019). Mulheres não devem ficar em silêncio. Arte, design, educação. São Paulo: Editorial Cortez.

Bauman, Z. (2017). Retrotopía. Barcelona: Paidós.

Benjamin, W. (2003). La obra de arte en la época de su reproductibilidad técnica. México: Itaca. 
Buckingham, D. (2008). Más allá de la tecnología. Aprendizaje infantil en la era de la cultura digital. Buenos Aires: Manantial.

Caeiro-Rodríguez, M. (2018). Aprendizaje Basado en la Creación y Educación Artística: proyectos de aula entre la metacognición y la metaemoción. Arte, Individuo y Sociedad, 30(1), 159-177. Doi: http://dx.doi.org/10.5209/ARIS.57043

Caeiro Rodríguez, M.; Muñiz de la Arena, M. A. (2019). La cognición expresiva como experiencia de relación del arte y la ciencia en la educación preuniversitaria. Artnodes, 24, 142-154. Doi: http://dx.doi.org/10.7238/a.v0i24.3259

Dominguez, R. (2019). Entornos personales de aprendizaje en la formación de docentes de Secundaria de la especialidad de Dibujo. Tesis doctoral. Universitat de València.

Dondis, D. A. (2017). La sintaxis de la imagen. Introducción al alfabeto visual. Barcelona: Gustavo Gili.

Duncum, P. (2015). Transforming Art Education into Visual Culture Education through Rhizomatic Structures, Anadolu Journal of Educational Sciences International, Art Education Special Issue, 47-64.

Fontal, O., García Ceballos, S. y Aso Morán, B. (2020). Desarrollo de competencias docentes en educación patrimonial mediante plataformas $2.0 \mathrm{y}$ entornos digitales como herramientas de aprendizaje, Investigación en la escuela, 101, 1-14.

Freire, P. (2015). Pedagogia da autonomia: saberes necessários à prática educativa. Rio de Janeiro: Paz e Terra.

Giroux, H. (2015). Flipping the Script: Rethinking Working-Class Resistance, Truthout, 8 .

Gómez Aguilella, M. J. (2018). Comunicar l'art a l'educació secundària. El projecte Second Round. Tesis doctoral. València: Universitat de València.

Haraway, D. (2019). Seguir con el problema. Generar parentesco en el Chthuluceno. Bilbao: Consonni.

Hernández Belver, M. y Ullán, A. M. (2017). Artistic creativity and dementia. A study for assessment by experts. Arte, Individuo y sociedad, 29, 127-138. Doi: https://doi.org/10.5209/ARIS.54453

Hernández-Hernández, F. y Sancho, J. M. y (2020). La investigación sobre historias de vida: de la identidad humanista a la subjetividad nómada. Márgenes, Revista de Educación de la Universidad de Málaga, 1(3), 34-45. Doi: https://doi.org/10.24310/ mgnmar.v1i3.9609 
Huerta, R. (2017). Transeducar. Arte, docencia y derechos lgtb. Barcelona: Egales. Huerta, R. (2019). Arte para Primaria. Barcelona: UOC.

Huerta, R. (2019). Arte, género y educación: diálogo en Brasil con Everson Melquiades, Vitória Amaral y Fabio Rodrigues. EARI. Educación Artística Revista de Investigación, 10, 198-209. Doi: https://doi.org/10.7203/eari.10.15732

Huerta, R. (2020). Arte, género y diseño en educación digital. València: Tirant lo Blanch.

Huerta, R. y Alonso-Sanz, A. (eds.) (2015). Educación Artística y Diversidad Sexual. Valencia: PUV.

Huerta, R. y Alonso-Sanz, A. (eds.) (2020). Humanidades digitales y pedagogías culturales. Saberes virales para una nueva educación. Barcelona: UOC.

Huerta, R., Alonso-Sanz, A. y Ramon, R. (eds.) (2018). Investigar y educar en diseño. València: Tirant lo Blanch.

Huerta, R., Alonso-Sanz, A. y Ramon, R. (2019). De película. Cine para educar en diversidad. València: Tirant lo Blanch.

Lovink, G. (2019). Tristes por diseño. Las redes sociales como ideología. Bilbao: Consonni.

Macharowski, A. (2019). Rafael Pérez Contel, precursor de la educación en artes visuales. Estudio de caso sobre su acción docente en centros valencianos. Tesis doctoral. Universitat de València.

Marín, R. y Roldán, J. (2017). Ideas visuales. Investigación Basada en Artes e investigación artística. Granada: Universidad de Granada.

Mascarell, D. (2017). Les TIC en la formació universitària de Mestres. El telèfon móvil en Didàctica de l'Expressió Plàstica a la Facultat de Magisteri de la Universitat de València. Tesis doctoral. Universitat de València.

Monleon, V. (2018). "El malo de la película". Estudio de las principales figuras malvadas de la colección cinematográfica clásicos Disney. EARI Educación Artística Revista de Investigación, 9, 131-148. Doi: https://doi.org/10.7203/eari.9.12212

Monleón, V. (2020). El malo de la película. Estudio de la maldad en la colección cinematográfica Clásicos Disney desde una pedagogía crítica. Tesis doctoral. Universitat de València.

Munari, B. (2020). El arte como oficio. Barcelona: Labor. 
Otxoteko, M. (2020). VJING. Estética y política de la imagen-ambiente. Artnodes, 25. Doi: http://doi.org/10.7238/a.v0i25.3325

Patiño, A. (2017). Todas las pantallas encendidas. Hacia una resistencia creativa de la mirada. Madrid: Fórcola.

Planella, J. (2017). Pedagogías sensibles. Sabores y saberes del cuerpo y la educación. Barcelona: Universitat de Barcelona.

Ramon, R. (2019). Prácticas artísticas de visualización entre cuerpo y objeto en entornos de mediación pedagógica. Arte, Individuo y Sociedad, 31(3), 509-526. Doi: $\underline{\text { https://dx.doi.org/10.5209/aris.60881 }}$

Ramon, R. y Alonso-Sanz, A. (2019). La deriva paralela pedagógica. Un hilo educativo invisible entre Porto y París a través de narrativas personales. Revista Portuguesa de Educação, 32(2), 74-90. Doi: http://dx.doi.org/10.21814/rpe.17200

Santamaría, A. (2019). Alta cultura descafeinada. Situacionismo low cost y otras escenas del arte en el cambio de siglo. Madrid: Siglo XXI Editores.

Soto González, M. D. (2015). Espacios de inclusión e implicaciones educativas entre escuela, museo y universidad. Análisis desde la investigación-acción. Tesis doctoral. Universitat de València.

Vidagañ, M. (2016). Museos, mediación cultural y artes visuales: perfiles profesionales del ámbito educativo. Tesis doctoral. Universitat de València. 